\title{
The stress singularity order in a composite wedge of functionally graded materials under antiplane deformation
}

\author{
Makhorkin M. I. ${ }^{1}$, Skrypochka T. A. ${ }^{2}$, Torskyy A. R. ${ }^{3}$ \\ ${ }^{1}$ Pidstryhach Institute for Applied Problems of Mechanics \\ and Mathematics National Academy of Sciences of Ukraine, \\ 3-b Naukova Str., 79060, L'viv, Ukraine \\ ${ }^{2}$ Lviv National Agrarian University, \\ 1 V. Velykogo Str., 80381, Dubliany, Ukraine \\ ${ }^{3}$ Centre of Mathematical Modelling of IAPMM NASU named after Ya. S. Pidstryhach, \\ 15 Dudaev Str. 79005, Lviv, Ukraine
}

(Received 22 October 2019; Revised 27 January 2020; Accepted 28 January 2020)

\begin{abstract}
In this paper, finding the order of singularity in multi-wedge systems containing elements made of functionally gradient material (FGM) with an angular gradient under antiplane deformation is studied. These elements are proposed to be modeled by means of multiwedge composite, where the shear modulus changes from wedge to wedge according to a certain functional dependence (in this article we consider the linear, quadratic, and exponential dependencies). It is found that the model region composed of 20 elements provides a relative error in the calculation of the stress field singularity order, which does not exceed $5 \%$. Using the simulation of FGM by a multi-wedge system, the influence of an insert made of functionally graded material with an angular gradient on the singularity order in a three-component composite wedge has been studied. A number of regularities have been established.
\end{abstract}

Keywords: antiplane problem, multi-wedge system, stress singularity, functionally graded material, angular gradient.

2010 MSC: 74B05, 74B99

DOI: $10.23939 / \mathrm{mmc} 2020.01 .039$

\section{Introduction}

When predicting the strength of composite structures, it is important to know the basic characteristic of the stress field behavior in the vicinity of "singular" points of the structure (for example, breakpoint of the materials contact surfaces, tips of the slit (cracks) and pointed inclusions, wedge-shaped notches and points of contact of several materials, etc.), namely the order of its singularity. This is, primarily, due to the fact that such points are concentrators of stresses, and their vicinities are the site of breakdown of the structure. Therefore, it is natural that the solution of the problem of determining the stress field singularity order in the vicinity of singular points of elastic structures is constantly in the center of attention of researchers. One of the first studies is described in the work of K. Wieghardt [1] (1907), their further development was carried out in the work of M. L. Williams [2]. An exhaustive list of works, concerning the results of study of the stress state in the vicinity of singular points in structures made of isotropic materials structures can be found in the reviews [3-8]. At the same place, the validity of modeling these regions by multi-wedge structures is substantiated.

With the advancement of technologies, functionally graded and anisotropic materials are increasingly being used in instrument-making, and therefore it becomes necessary to analyze the stress state around the "singular" points existing in such materials [3,6-11].

A thorough review of works concerning determination of the singular order around an apex of a multi-wedge systems is given in publications $[3,7-9]$. There are can find the analytical and numerical methods for determining the stress-strain state in multi-wedge systems. At the same place their specific configurations are investigated [4,7-10]. Bat the number of elements of these systems generally did not 
exceed four. This is due to the fact that the use of analytical approaches (complex potentials or Mellin transform) $[4,7,11,12]$ leads to the need of solving a system of equations of order $2 n$ for antiplane problem and $4 n$ for a plane one. And the numerical methods $[14,15]$ require serious improvements, especially in the study of systems containing elements with small opening angles. This may explain the fact that there currently are no detailed studies of the behavior of the stress field singularity around the vertex of a multi-wedge system in the case when the number of its elements will increase (and the size of their opening angles will decrease, respectively) while maintaining the original geometry of the system.

In the papers $[7,15,16]$, the singularity of stresses in the vicinity of a "singular" point in the structure containing the elements of FGM with angular gradient is studied. That is, the material the elastic characteristics of which continuously varied in angular polar coordinate, the pole of which coincides with the "singular" point. At the same place, based on the approximation of elastic characteristics by a piecewise constant function, the possibility of approximate determination of the singularity of stresses is considered. The special case of determining the order of singular stresses in a composite wedge with an FGM insert at the assumption that its shear modulus varies by quadratic law, was considered in the publication [16]. There the influence of elastic characteristics of external wedges on the order of singularity is also investigated. However, despite the sufficient number of works involved in the mentioned problems (reviews $[6,14,16]$ ), the question of the influence of the characteristics variation laws on the description of the stress state in the vicinity of the corresponding "singular" points remains open. It should also be noted that the special form of expressions for the displacements and stresses fields in materials with angular gradients creates additional difficulties when formulating the conditions of contact with an isotropic material. This in turn leads to difficulties with the study of stress-strain state in composites containing inserts materials with elastic characteristics varied by angular coordinate.

The purpose of this article is to test one approach of modeling material with angular gradient and to study the antiplane deformation of a composite wedge with an FGM insert. For this purpose, is analyzed the possibility of modeling the wedge-shaped elements of material with a functional gradient by a multi-wedge package of similar geometry whose elements elastic properties varied according to a corresponding functional dependence.

The results of the analysis are used to study the longitudinal shear of a three-component wedge, the central element of which is made of FGM with angular gradient. Such an object of research was chosen, in particular, for physical speculations about the diffusion of materials during their technological connection $[7,13,16]$, as a result in the vicinity of the breakpoint of the material separation boundary is appear a wedge-shaped interphase, the elastic characteristics of which changes according to some predefined law.

\section{Basic relations and problem statement}

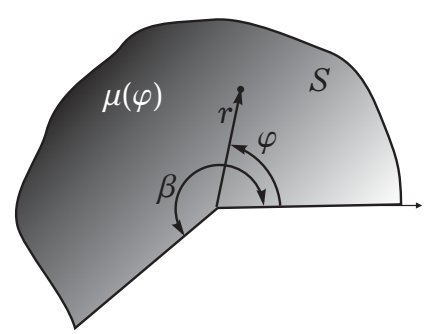

Fig. 1. A wedge of functionally gradient material, the shear modulus of which changes in the angular direction.
Let us consider the antiplane deformation of an infinite wedge $S$ (Fig. 1) with an opening angle $\beta \leqslant 2 \pi$ at the vertex, whose elastic characteristics of material are varying continuously depending on the angular coordinate according to a certain law $\mu=\mu(\varphi)$ (FGM with angular gradient).

According to the elasticity theory of inhomogeneous body in this region the equilibrium equation, will look like [17]:

$$
\frac{\partial^{2} w}{\partial r^{2}}+\frac{1}{r} \frac{\partial w}{\partial r}+\frac{1}{r^{2}} \frac{\partial^{2} w}{\partial^{2} \varphi}+\frac{1}{\mu(\varphi) r^{2}} \frac{d \mu(\varphi)}{d \varphi} \frac{\partial w}{\partial \varphi}=0
$$

and at the edges of the wedge the conditions of the corresponding boundary-value problem of elasticity theory are specified: 
the first conditions

$$
\left.\sigma_{\varphi z}(r, \varphi)\right|_{\varphi=0}=\tau_{0}(r, \varphi),\left.\quad \sigma_{\varphi z}(r, \varphi)\right|_{\varphi=\beta}=\tau_{\beta}(r, \varphi)
$$

the second conditions

$$
\left.w(r)\right|_{\varphi=0}=w_{0}(r),\left.\quad w(r)\right|_{\varphi=\beta}=w_{\beta}(r)
$$

the mixed conditions

$$
\left.\sigma_{\varphi z}(r, \varphi)\right|_{\varphi=0}=\tau_{0}(r, \varphi),\left.\quad w(r)\right|_{\varphi=\beta}=w_{\beta}(r)
$$

or

$$
\left.w(r)\right|_{\varphi=0}=w_{0}(r),\left.\quad \sigma_{\varphi z}(r, \varphi)\right|_{\varphi=\beta}=\tau_{\beta}(r, \varphi) .
$$

In this article, the special cases, where the shear modulus changes according to one of the following laws $[7,14,16]$ will be consider:

the liniar law

$$
\mu(\varphi)=\varphi a+b, \quad 0<\varphi<\beta
$$

the quadratic law

$$
\mu(\varphi)=\{a \varphi+b\}^{2}, \quad 0<\varphi<\beta
$$

the exponential law

$$
\mu(\varphi)=b e^{a \varphi}, \quad 0<\varphi<\beta .
$$

Hear $a, b$ are the arbitrary constants.

According to the works $[5,18]$, the stress field near the top of the wedge can be writing as a power series

$$
\sigma(r, \varphi)=\sum_{i=0}^{\infty} \mu \frac{\partial \tilde{w}_{i}(\varphi)}{\partial \varphi} r^{q_{i}-1}
$$

where $r$ is the distance to a specific point; $q_{i}$ are the roots of the characteristic equation $\Delta(q)=0$, $\operatorname{Re}\left(q_{i}\right) \in(0 ; 1)$;

Therefore, the displacement field will be described by an asymptotic series of the form

$$
w(r, \varphi)=\sum_{i=0}^{\infty} \tilde{w}_{i}(\varphi) r^{q_{i}}
$$

where the analytical solutions (1) are found in the form: $\tilde{w}_{i}(\varphi)=A_{i} J_{0}\left(\frac{b q_{i}}{a}+q \varphi\right)+$ $B_{i} Y_{0}\left(\frac{b q_{i}}{a}+q \varphi\right)$ for linear law; $\tilde{w}_{i}(\varphi)=\frac{A_{i} \cos q_{i} \varphi+B_{i} \sin q_{i} \varphi}{a \varphi+b}$ for quadratic law [16]; $\tilde{w}_{i}=$ $\mathrm{e}^{-0.5 a \varphi}\left[A_{i} \cos \left(0.5 \sqrt{4 q_{i}^{2}-a^{2}} \varphi\right)+B_{i} \sin \left(0.5 \sqrt{4 q_{i}^{2}-a^{2}} \varphi\right)\right]$ for exponential law.

Using the boundary conditions (2), is finding the form of the characteristic equation for the case of the first boundary-value problem of elasticity theory similarly to one [5, 18]:

for linear law

$$
q^{2}\left[J_{1}\left(b a^{-1} q\right) Y_{1}\left(q\left(b a^{-1}+\beta\right)\right)-J_{1}\left(q\left(b a^{-1}+\beta\right)\right) Y_{1}\left(b a^{-1} q\right)\right]=0,
$$

for quadratic law

$$
\left(1+q^{2}\left(b^{2} a^{-2}+b a^{-1} \beta\right)\right) \sin q \beta-q \beta \cos q \beta=0,
$$

for exponential law

$$
q^{2} \sin \left(0.5 \sqrt{-a^{2}+4 q^{2}} \beta\right)=0 .
$$

The characteristic equations for the cases of the second or mixed problems of elasticity theory and for a solid plate have a similar structure. 
In works $[14,19]$ the stresses singularity order in a multi-wedge system, whose elastic characteristics of elements are related by a functional dependence (Fig. $2 a$ ) is investigated. It is found that the number of elements increases, while preserving its initial geometry configuration, asymptotically goes to a certain limit value. Also, it is revealed that when the number of elements is $n>20$, the relative difference in the calculation of the values of the singularity order for different number of elements $n$ of the system does not exceed $\varepsilon=\left|\left(\lambda_{n}-\lambda_{n+k}\right) \lambda_{n}^{-1}\right|=0.01(n, k=1,2, \ldots$,$) [19]. In the same place is$ proposed to use such models to study the stress fields in the vicinity of "singular points" of structures made of FGM with angular gradient.

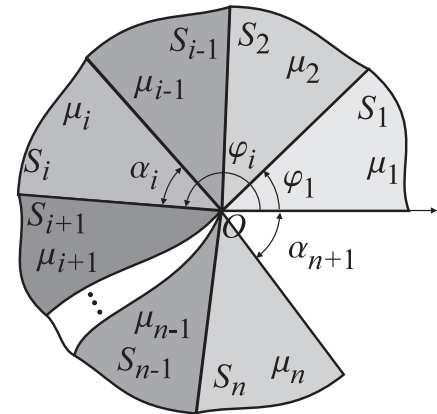

$a$

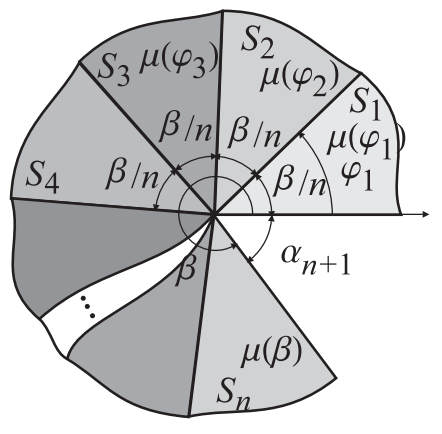

$b$

Determination of the order of singularity in a multi-wedge system composed of an arbitrary number $n$ of connected different elastic, isotropic wedges $S_{i}(i=1,2, \ldots, n)$ (Fig. $\left.2 a\right)$, under the conditions of longitudinal shear $u=$ $0, v=0, w=w(r, \varphi)$, is discussed in detail in the works $[5,6]$. According to these works, the stress singularity order in the vicinity of the vertex of the system point $O$, is determined by the relations $\lambda_{i}=1-\operatorname{Re}\left(q_{i}\right)$, where $q_{i}$ are the roots of the characteristic equation $\Delta(q)=0$, whose real part belongs to the interval $\operatorname{Re}\left(q_{i}\right) \in(0 ; 1)$. Depending on the boundary conditions given on the edges, the characteristic equation for antiplane deformation, has the form [6]:

1) for the conditions of the first boundary-value problem of elasticity theory

$$
q \sin \left(q \varphi_{n}\right)+\sum_{i=1}^{n-1} \frac{\mu_{i+1}-\mu_{i}}{\mu_{i+1}} L_{1}^{i} \cos \left[q\left(\varphi_{n}-\varphi_{i}\right)\right]=0 ;
$$

2) for the conditions of the second boundary value problem

$$
\sin \left(q \varphi_{n}\right)-\sum_{i=1}^{n-1} \frac{\mu_{i+1}-\mu_{i}}{q \mu_{i+1}} L_{2}^{i} \sin \left[q\left(\varphi_{n}-\varphi_{i}\right)\right]=0 ;
$$

3) for the conditions of the mixed boundary value problems

$$
\cos \left(q \varphi_{n}\right)-\sum_{i=1}^{n-1} \frac{\left(\mu_{i+1}-\mu_{i}\right)}{q \mu_{i+1}} L_{1}^{i} \sin \left[q\left(\varphi_{n}-\varphi_{i}\right)\right]=0,
$$

the loads are specified at $\varphi=0$, and displacement at $\varphi=\varphi_{n}$;

$$
q \cos \left(q \varphi_{n}\right)-\sum_{i=1}^{n-1} \frac{\mu_{i+1}-\mu_{i}}{\mu_{i+1}} L_{2}^{i} \cos \left[q\left(\varphi_{n}-\varphi_{i}\right)\right]=0,
$$

the loads are specified at $\varphi=\varphi_{n}$, and displacement at $\varphi=0$.

Here

$$
\begin{aligned}
& L_{1}^{k}=-q \sin q \varphi_{k}-\sum_{i=1}^{k-1} \frac{\left(\mu_{i+1}-\mu_{i}\right)}{\mu_{i+1}} L_{1}^{i} \cos \left[q\left(\varphi_{k}-\varphi_{i}\right)\right], \\
& L_{2}^{k}=q \cos q \varphi_{k}-\sum_{i=1}^{k-1} \frac{\left(\mu_{i+1}-\mu_{i}\right)}{\mu_{i+1}} L_{2}^{i} \cos \left[q\left(\varphi_{k}-\varphi_{i}\right)\right] .
\end{aligned}
$$

If now is assumed that the opening angles of the composite components are $\alpha_{i}=\beta n^{-1}$ and the shear modulus are related by one of the functional dependencies (6)-(8), for example by the equality $\mu_{i}=\mu\left(\varphi_{i}\right)$ (where $\varphi_{i}=i \beta n^{-1}, i=\overline{1, n}$ ), then this composite (Fig. 2b) according to [15, 19] models a wedge with opening angle $\beta$ at the vertex made of FGM with angular gradientness (Fig. 1) 


\section{Results and analysis}

Based on the above results, is investigated the variation of singularity order in a wedge made of FGM, the shear modulus of which changes in the transversal direction according to one of the laws (6)-(8), depending on the opening angle $\beta$ of the wedge and the ratio of shear modulus values on the edges of the wedge $\gamma=\mu(\beta) / \mu(0)$.

The approximate values of the singularity order were calculated using the modeling FGM with angular gradient by the multi-wedge system and solution of characteristic equations (14)-(17). For verification, they were compared with the exact values obtained using the model of material with continuous heterogeneity (1) based on the solutions of characteristic equations (11)-(13). It is found that the maximum relative error in the calculation of the singularity order using the model region composed of 20 wedges is less than $5 \%$ for the ratio of the shear modules at the edges of the wedge $0.01<\gamma<100$ and decreases with increasing their number.

The typical results of the singularity order calculations are presented in Fig. 3, where the solid curves 1, 2, 3 correspond

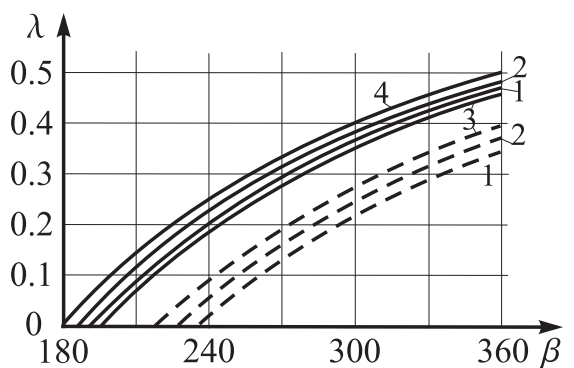

Fig. 3. The maximum value of the stress singularity order $\lambda_{i}=1-\operatorname{Re}\left(q_{i}\right)$ in a wedge made of FGM with angular gradient in the case of the first boundary value problem.

to the quadratic, exponential, and linear laws of the shear modulus variation at $\gamma=5$, and the dash one corresponds to $\gamma=125$. The curve 4 corresponds to the case of a homogeneous isotropic wedge $\gamma=1$.

It is elucidated that the stress field singularity near the vertex of the wedge occurs because to the value of the opening angle $\beta$ is larger than a certain limit value $\alpha$, that is $\beta>\alpha \geqslant 180^{\circ}$. In the case of a wedge of isotropic material $\alpha=180^{\circ}$ is the opening angle, at which the wedge can be considered as a matrix with a wedge-shaped cut.

The following patterns have been identified:

- as the ratio of the shear modulus increases at $\gamma>1$ (or decreases at $1>\gamma>0$ ), the limit value of wedge opening angle $\alpha$ increases, and the value of the singularity order decreases;

- the value of the order of singularity in a wedge of FGM with an angular gradient is always less than in the isotropic wedge and this difference is larger the larger (or less) is the value of the ratio of shear modulus on the edges of the wedge $\gamma$;

- usage of an approximation of the FGM properties with an angular gradient by means of a quadratic law leads to lower values of the singularity order in comparison with the use of the exponential law.

These results indicate that the FGM wedge-shaped elements (inserts) with angular gradient can be reasonably modeled by the multiwedge structures the elastic characteristics of the elements of which are related by a certain functional dependence.

Based on this conclusion, an FGM insert in a composite threecomponent wedge was modeled (Fig. 4a).

Here $\alpha_{1}^{*}, \alpha_{3}^{*}, \mu_{1}^{*}, \mu_{3}^{*}$ are the open-

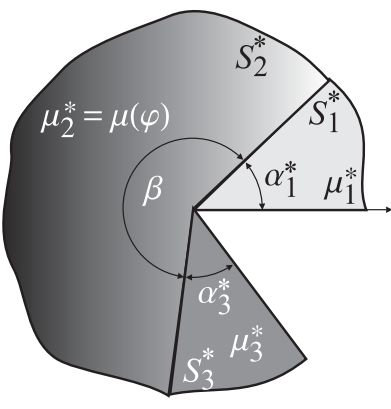

$a$

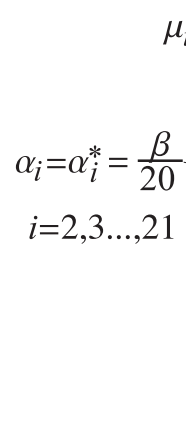

$\mu_{i}=\mu\left(\varphi_{i}\right)$

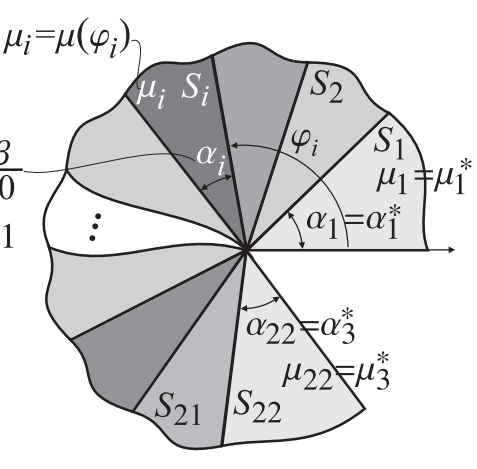

$b$

Fig. 4. Three-component composite wedge containing insert of functionally graded material.

ing angles and the shear modulus of the external wedges $S_{1}^{*}, S_{3}^{*}$ Fig. $4 a ; n=20$ is the number of wedges of the system by which we model the insert $S_{2}^{*}$ Fig. $4 b ; \beta$ is the opening angle of the insert; shear modulus of the insert $S_{2}^{*}$ material Fig. $4 a$ changes from $\mu\left(\alpha_{1}^{*}\right)=\mu_{1}^{*}$ to $\mu\left(\alpha_{1}^{*}+\beta\right)=\mu_{3}^{*}$ according to one of 
the typical laws of change of the shear modulus (6)-(8), where $\alpha_{1}^{*}<\varphi<\alpha_{1}^{*}+\beta$, and the coefficients $a$ and $b$ are determined according to the relations [20]:

$a=\left(\mu_{3}^{*}-\mu_{1}^{*}\right) \beta^{-1}, b=\left[\mu_{1}^{*} \beta-\alpha_{1}^{*}\left(\mu_{3}^{*}-\mu_{1}^{*}\right)\right] \beta^{-1}$ in the case of linear law of the shear modulus change; $a=\left(\sqrt{\mu_{3}^{*}}-\sqrt{\mu_{1}^{*}}\right) \beta^{-1}, b=\left[\alpha_{1}^{*} \sqrt{\mu_{3}^{*}}-\left(\alpha_{1}^{*}+\beta\right) \sqrt{\mu_{1}^{*}}\right] \beta^{-1}$ in the case of quadratic law;

$a=(\beta)^{-1} \ln \gamma, b=\mu_{1}^{*} \gamma^{-\frac{\alpha_{1}^{*}}{\beta}}, \mu_{1}^{*} \gamma=\mu_{3}^{*}$ in the case of exponential law.

Some typical results of numerical studies of the influence of the insert shear modulus functional dependence type on the stress singularity order, depending on the insert opening angle, are presented graphically in Figs. 5-7.

These results correspond to the systems for which $\alpha_{1}^{*}+\beta+\alpha_{3}^{*}=2 \pi$ (the angular cutout transforming into a section), the opening angles of the external wedges are the same $\left(\alpha_{1}^{*}=\alpha_{3}^{*}\right)$, and the ratio of their shear modules $\gamma=\mu_{3}^{*} / \mu_{1}^{*}=10$ under the conditions of the first (Fig. 5), the second (Fig. 6) and mixed (Fig. 7) boundary value problems. The curves 1-3 in the figures illustrate the corresponding results of determining the stress singularity order for linear, quadratic, and exponential type variation of the insert $S_{2}^{*}$ shear modulus.

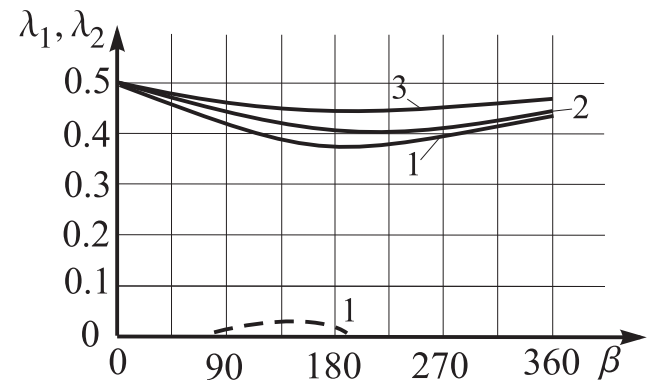

Fig. 5. The values of the singularity order $\lambda_{1}$ (solid line) and $\lambda_{2}$ (dashed line) for the first-boundary value problem of elasticity theory.

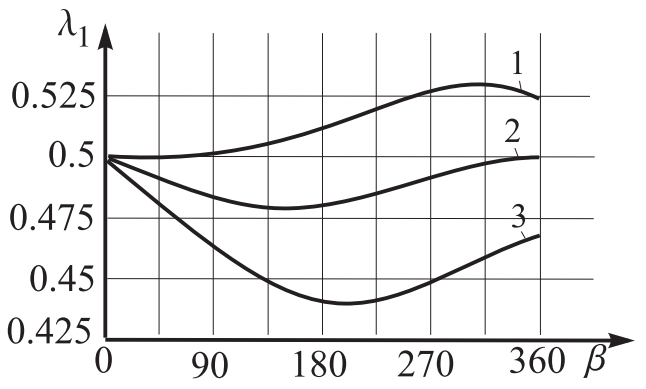

Fig. 6. The values of the singularity order $\lambda_{1}$ for the second boundary-value problem of elasticity theory.

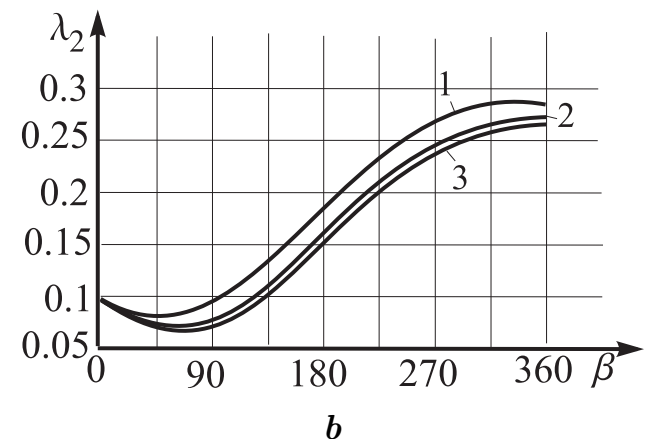

Fig. 7. The values of the singularity order $\lambda_{1}$ and $\lambda_{2}$ for the mixed problem of elasticity (the forces are given at $\varphi=0$, displacement at $\varphi=\varphi_{n}$, and the ratio of the shear modules of external wedges is $\mu_{3}^{*} / \mu_{1}^{*}>1$.

The results show that:

- for the first boundary-value problem (Fig. 5), the singularity order $\lambda_{1}=0.5$ with increasing the insert opening angle decreases from the value $\lambda_{1}=0.5$ (absence of the insert), and then increases, while remaining less than $\lambda_{1}=0.5$, even when considering the crack in the matrix of FGM. The minimum singularity order value is obtained by the degeneracy of the insertion to the half-plane $\beta=\pi$. The influence of the law of change of the shear modulus of the insert material manifests itself by the fact that the smallest values of the singularity order will be for the insert made of material whose shear modulus changes linearly, and the largest will be for those whose shear modulus changes exponentially; 
- for the second boundary-value problem of the elasticity theory (Fig. 6), the values of the singularity order will be the smallest if the shear modulus of the insert material varies according to the exponential law, and the largest when it varies linearly. If the change of the shear modulus is described by the exponential law, the singularity order changed in the same way as for the first boundary value problem: its values first decrease with increasing the angle of insertion, and then increase, while remaining less than $\lambda_{1}=0.5$. In the case of a quadratic law of the insert shear modulus variation the singular order value increase after reaching the minimum and for $\beta \approx 2 \pi$, they are approximately equal to 0.5 . If the variation of the insert shear modulus is given by a linear law, then for values $\beta<\pi / 2$ the singularity order is about $\lambda_{1} \approx 0.5$. For $\beta>\pi / 2$, it grows to maximum at $\beta \approx 5 \pi / 3$, then falls, while remaining greater than 0.5 .

- for the mixed problem of elasticity (Fig. 7), besides the maximum stress singularity order $\lambda_{1}$ (Fig. $7 a$ ), it is necessary to take into account the minor one $\lambda_{2}$ (Fig. $7 b$ ). The maximum values of the singularity order $0.84<\lambda_{1}<0.905$ for different laws of change of the Poisson ratio of the insert material differ a little from each other, and for $\beta<\pi$ they are almost equal. The greatest value of the singularity order is obtained for exponential law of the insert shear modulus variation while the smallest one occurs for the linear law. If the system is under the condition of mixed problem of elasticity theory, then in addition to the maximum values $\lambda_{1}$ on interval $(0 ; 1)$, there are also minor values of the singularity order belonging to the interval $(0.05 ; 0.3)$ (Fig. $7 b)$. Then the singularity generated by them becomes essential, and therefore, when evaluating the stress-strain state in the structure of considered type, one must take into account the term of the series (9) that contains them. The largest values $\lambda_{2}$ are obtained if the shear modulus of the insert varies linearly while the smallest one is observed for the exponential law (Fig. $7 b$ ).

For the first and second boundary-value problems of the elasticity theory, there may also be more than one value of the singularity order (for example, the first boundary-value problem, when the shear modulus of the insert material changes linearly (Fig. 5)) for different geometric parameters of the system. However, in these cases $q_{2} \approx 1$ and, the singularity generated by it is small $\lambda_{2} \ll 1$. Therefore we can when describing the stress field around the vertex of the wedge system, neglects the corresponding member of series $(9),[16,20]$.

\section{Conclusions}

A procedure for determining the stress singularity order in the vicinity of a singular point of a wedgeshaped structure containing elements of FGM with an angular gradient is proposed. The procedure is based on modeling the FGM elements by multi-wedge systems, whose elastic characteristics are related by functional dependence.

By using a model region composed of 20 wedges, it is found that the maximum relative error of the stress singularity order in the studied cases is less than $5 \%$ for the ratio of shear modulus value on the edges of the wedge is $1<\gamma<100\left(\gamma=\mu(\beta) \mu^{-1}(0)\right)$. This confirms the validity of using such a model.

This model was used to elucidate the singularity order in a two-component wedge with an FGM insert with an angular gradient. The influence of the insert shear modulus variation law nature on the stress singularity order is analyzed. It is found that depending on the geometric parameters of the system, being implemented the variation law of the shear modulus of FGM insert, one can influence significantly the stress field singularity order.

The proposed procedure provides additional possibility in designing and predicting the integrity and reliability of structures containing wedge-happen FGM elements with an angular gradient.

[1] Wieghardt K. Über das Spalten und zerreissen elastischer Körper. Z. Math. Phys. 55, 60-103 (1907).

[2] Williams M. L. Stress singularities resulting from various boundary conditions in angular corners of plates in extension. Journal of Applied Mechanics. 19 (4), 526-528 (1952).

Mathematical Modeling and Computing, Vol.7, No. 1, pp. 39-47 (2020) 
[3] Savruk M., Kazberuk A. Stress concentration at notches. Springer International Publishing AG (2016).

[4] Paggi M., Carpinteri A., Orta R. A mathematical analogy and a unified asymptotic formulation for singular elastic and electromagnetic fields at multimaterial wedges. Journal of Elasticity. 99 (2), 131-146 (2010).

[5] Makhorkin M., Makhorkina T. Analytical determination of the order of stress field singularity in some configurations of multiwedge systems for the case of antiplane deformation. Econtechmod. An international quarterly journal. 6 (3), 45-52 (2017).

[6] Makhorkin M., Sulym H. On determination of the stress-strain state of a multi-wedge system with thin radial defects under antiplane deformation. Civil and environmental engineering reports. 5, 235-251 (2010).

[7] Carpinteri A., Paggi M. On the asymptotic stress field in angularly nonhomogeneous materials. Int. J. Fract. 135 (4), 267-283 (2005).

[8] Carpinteri A. Paggi M. Singular harmonic problems at a wedge vertex: mathematical analogies between elasticity, diffusion, electromagnetism, and fluid dynamics. Journal of Mechanics of Materials and Structures. 6 (1-4), 113-125 (2011).

[9] Fedorov A. Yu., Matveenko V. P. Investigation of stress behavior in the vicinity of singular points of elastic bodies made of functionally graded materials. J. Appl. Mech. 85 (6), 061008-1-061008-13 (2018).

[10] Hu X. F., Yao W. A., Yang S. T. A symplectic analytical singular element for steady-state thermal conduction with singularities in anisotropic material. J. of heat transfer. 140 (9), 091301-1-091301-13 (2018).

[11] Xiaofei H. Stress singularity analysis of multi-material wedges under antiplane deformation. Acta Mech. Solida Sinica. 26 (2), 151-160 (2013).

[12] Tranter C. J. The use of the Mellin transform in finding the stress distribution in an infinite wedge. Quarterly Journal of Mechanics and Applied Mathematics. 1, 125-130 (1948).

[13] Marur P. R., Tippur H. V. Numerical analysis of crack-tip fields in functionally graded materials with a crack normal to the elastic gradient. Int. J. Solids Struct. 37, 5353-5370 (2000).

[14] Linkov A., Rybarska-Rusinek L. Evaluation of stress concentration in multi-wedge systems with functionally graded wedges. International Journal of Engineering Science. 61, 87-93 (2012).

[15] Linkov A. M., Koshelev V.F. Multi-wedge points and multi-wedge elements in computational mechanics: evaluation of exponents and angular distribution. Int. J. Solids and Structures. 43, 5909-5930 (2006).

[16] Tikhomirov V. V. Stress singularity in a top of composite wedge with internal functionally graded material. St. Petersburg Polytechnical University J.: Physics and Mathematics. 1 (3), 278-286 (2015).

[17] Lomakyn V. A. Theory of elasticity of inhomogeneous bodies. Moscow, MGU (1976), (in Russian).

[18] Parton V., Perlin P. Mathematical methods of the theory of elasticity. Two volumes. Mir (1984).

[19] Makhorkin M. I., Skrypochka T. A. Stress singularity in a multiwedge system with interconnected elastic characteristics of its elements, under antiplane deformation. Visnyk of Zaporizhzhya National University. Physical and mathematical Sciences. 2, 170-179 (2017), (in Ukrainian).

[20] Makhorkin M. Effect of a wedge type insert of the functionally graded materialon the stress singularity in a composite wedge structure under antiplane deformation. Applied problems of mechanics and mathematics. Scientific proceeding. 16, 112-118 (2018), (in Ukrainian). 


\title{
Порядок сингулярності напружень у композитному клині 3 функціонально-градієнтних матеріалів за антиплоскої деформації
}

\author{
Махоркін М. I. ${ }^{1}$, Скрипочка Т. А. ${ }^{2}$, Торський А. Р. ${ }^{3}$ \\ ${ }^{1}$ Інститут прикладних проблем Механіки і математики ім.Я.С. Підстригача НАН Украйни, \\ вул. Наукова, 3-б, Лъвів, 79060, Украӥна \\ 2 Львівський національний аграрний університет, \\ вул. В. Великого, 1, Дубляни, 80381, Україна \\ ${ }^{3}$ Центр математичного моделювання ІППММ ім. Я. С. Підстригача, \\ вул. Дж. Дудаєва, 15, Львів, 79005, Украӥна
}

\begin{abstract}
У даній роботі вивчається з'ясування порядку сингулярності у багатоклинових системах, що містять елементи, виконані з функціонально градієнтного матеріалу (ФГМ) з кутовою градієнтністю. Такі елементи запропоновано моделювати за допомогою багатоклинового пакету, де модуль зсуву змінюється від клина до клина згідно з певною функціональною залежністю (в статті розглянуто лінійну, квадратичну та експоненціальну залежності). З'ясовано, що складена з 20 елементів модельна область забезпечує відносну похибку обчислення порядку сингулярності поля напружень, яка не перевищує $5 \%$. Використовуючи моделювання ФГМ за допомогою багатоклинової системи, вивчено вплив вставки з ФГМ з кутовою градієнтністю на порядок сингулярності у трикомпонентному композитному клині. Виявлено низку закономірностей.
\end{abstract}

Ключові слова: антиплоска задача, багатоклинова система, сингулярність напружень, функціонально градієнтний матеріал, кутова градієнтність. 